\title{
A Análise Fílmica no Contexto do Deslocamento Forçado de uma Comunidade: Articulações entre a Psicologia e a Cultura,***
}

\author{
Jonas Carvalho e Silva ${ }^{1, * * *}$ (D) \& Júlia Sursis Nobre Ferro Bucher-Maluschke ${ }^{2}$ (D) \\ ${ }^{1}$ Technische Universität Dortmund, Dortmund, Alemanha \\ ${ }^{2}$ Universidade de Brasilia, Brasília, DF, Brasil
}

\begin{abstract}
RESUMO - Os deslocamentos forçados na Amazônia são um padrão migratório que envolve os estudos de diferentes disciplinas. O objetivo deste estudo foi identificar as experiências das famílias no contexto do deslocamento forçado registradas no documentário "Pinheirópolis, vida, festa, futuro...”, dirigido por José Iramar em 2000, à luz da Teoria dos Sistemas Bioecológicos. Após a decupagem das cenas e as transcrições dos depoimentos, foram geradas as nuvens de palavras e organizadas as categorias de análise: (a) formação do povoado, (b) atividades econômicas, (c) reações/sentimentos ao deslocamento, (d) o último festejo e o luto antecipatório. O método fílmico possibilitou adquirir informações do período anterior à remoção, o que sugere a utilização deste recurso nos estudos avaliativos sobre as comunidades impactadas por barragens.
\end{abstract}

PALAVRAS-CHAVE: migração interna, Amazônia, recursos audiovisuais, ecologia humana

\section{Film Analysis in the Context of Forced Displacement in a Community: Links between Psychology and Culture}

\begin{abstract}
Forced displacements in the Amazon region are a migratory pattern that involves studies of various disciplines. The objective of this paper was to identify the experiences of the families in the context of a forced displacement registered in the documentary "Pinheirópolis, vida, festa, futuro...", directed by José Iramar in 2000, based on Theory of Bioecological Model. After decoupling the scenes and the transcriptions of the narratives, the analysing categories were identified: (a) formation of the village, (b) economic activities; (c) response / feelings towards the displacement; (d) the last festivity and anticipatory mourning. The filmic method enables us to obtain information from the pre-relocation, suggesting the use of this tool in evaluative research about the communities impacted by dams.
\end{abstract}

KEYWORDS: internal migration, Amazon, audiovisual aids, human ecology

A análise dos conteúdos fílmicos circula nas representações da mídia de modo que possibilita explicações alternativas sobre os impactos psicossociais da migração (Ramos, 2003; Serafim \& Ramos, 2016). Este estudo analisa um documentário sobre a remoção de uma comunidade atingida pela construção de uma Usina Hidrelétrica (UHE), para identificar e descrever os padrões específicos das experiências dessa população. Baseado nos pressupostos do Modelo Bioecológico do Desenvolvimento Humano
(Bronfenbrenner \& Morris, 2007), sugere-se que os deslocamentos estruturam a migração em experiências, identificação e funcionamentos psíquicos, em uma hierarquia sistêmica que depende das vivências comunitárias no contexto.

No contexto desta pesquisa, os deslocamentos forçados na Amazônia são um fenômeno migratório que atinge as populações tradicionais, e até municípios maiores, alvos de grandes empreendimentos ambientais (Athayde et al., 2019; Instituto Igarapé, 2018; Pinto, 2012). Destes

\footnotetext{
* Trabalho derivado da tese de doutorado do primeiro autor, orientado pela segunda autora

** Apoio: CAPES, CNPq, FAPDF e Fundação Alexander von Humboldt.

***E-mail: carvalho707@gmail.com

- Submetido: 09/10/2019; Revisado: 09/12/2019; Aceito: 23/03/2020.
} 
destacam-se o cultivo extensivo da soja, a exploração de usinas e agropecuárias, que promovem a marginalização de comunidades rurais que utilizam basicamente os recursos naturais disponíveis para o sustento (Jesus \& Ertzogue, 2018; Parente, 2015). Estes eventos se referem a quando as pessoas migram a outros ambientes em consequência das condições de existências que, em geral, não lhes garantem os direitos que as correspondem como cidadãs: o direito ao trabalho, a educação, saúde e a segurança (Carvalho e Silva \& Bucher-Maluschke, 2018; Spurrier, 2013).

As sociedades indígenas são tidas como os núcleos mais importantes dessas diversidades. Entretanto, outros são incluídos: remanescentes de quilombos, babaçueiros, pantaneiros, pescadores artesanais, ribeirinhos e seringueiros (Athayde \& Silva-Lugo, 2018; Menestrino \& Parente, 2011). Cada um apresenta sistemas próprios de relação com o ambiente e com o meio, ocupam a região por gerações, sem o registro legal da propriedade privada da terra. Definem apenas o local de moradia, como uma parcela individual, e o restante do território torna-se de uso comunitário, geralmente regulamentado pelo costume e por normas compartilhadas internamente (Zagallo \& Ertzogue, 2018).

O deslocamento de pessoas do seu habitat, em razão da construção de hidrelétricas, causa danos às comunidades impactadas, tais como o rompimento de laços afetivos, de vizinhança e a desestruturação do modo de vida das populações (Carvalho e Silva \& Ertzogue, 2015; Zagallo \& Ertzogue, 2018). Os pesquisadores de distintas áreas do conhecimento apresentam em seus dados o inconformismo das famílias atingidas por barragens pelo rompimento desses vínculos comunitários e a desestruturação familiar (Athayde \& Silva-Lugo, 2018; Carvalho e Silva, 2018; Jesus \& Ertzogue, 2018; Parente, 2015; Silva Marques et al., 2018).

Neste sentido, Silva Marques et al. (2018) analisaram as vivências de 43 indivíduos que sofreram o deslocamento forçado devido a construção da Hidrelétrica de Itá no Brasil. Os autores observaram as interfaces desse processo com a saúde mental, no que tange as situações de violência e de violação dos direitos dos atingidos, além das transformações ambientais. Os participantes da pesquisa caracterizaram o território alagado como uma extensão do corpo e da identidade, como espaço de vida, trabalho, relações sociais, lutas e intensivo investimento afetivo.

Os estudos em Psicologia sobre a migração seguem os modelos orientados pela American Psychological Association (APA), a exemplo do Relatório Força Tarefa Presidencial sobre a Imigração (APA, 2012), que orienta a pesquisa e a intervenção dos fenômenos migratórios na perspectiva sócio ecológica adaptada da Teoria do Modelo Bioecológico. Bronfenbrenner (1986) elucida o ambiente ecológico como um arranjo aninhado de estruturas concêntricas e interativas, onde o contexto é a interação de três núcleos básicos: o processo, a pessoa e o tempo. A abordagem lança mão de outras disciplinas para a construção de métodos de pesquisas sobre o desenvolvimento humano em sistemas complexos (Brady, 2019).

Neste modelo teórico o processo é considerado o principal mecanismo promotor do desenvolvimento, que é compreendido através da interação recíproca e complexa de um indivíduo ativo, e em evolução, com as pessoas, os objetos e os símbolos presentes no ambiente imediato (Bronfenbrenner \& Morris, 1998; Hirani \& Richter, 2019). A pessoa é analisada por meio de suas características determinadas e aquelas construídas na interação com o ambiente. O contexto é analisado através da interação de quatro níveis ambientais. O tempo permite examinar a influência para o desenvolvimento humano das mudanças e as continuidades que ocorrem ao longo do ciclo vital.

Para auxiliar a compreensão dos quatro níveis ambientais do contexto e do tempo, a Figura 1 mostra no centro o microssistema, ambiente imediato, onde se estabelecem as relações diretas, no qual os processos proximais operam para produzir e sustentar o desenvolvimento. A agregação desses vários microssistemas origina o mesossistema. $\mathrm{O}$ exossistema se constitui nas relações e nos processos que ocorrem entre dois ou mais conceitos, sendo que um não tem relação direta com a pessoa, embora influencie indiretamente os processos no ambiente imediato em que a pessoa vive. As leis, regras e normas de uma determinada sociedade compõem o macrossistema. O cronossistema se refere ao tempo histórico, como uma propriedade do ambiente e não somente do curso de vida.

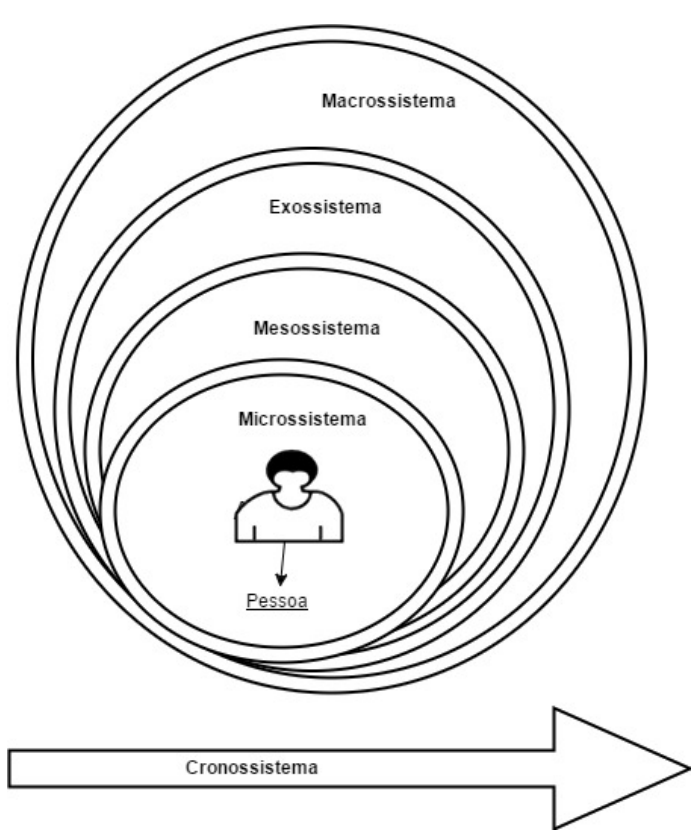

Figura 1. Sistemas da Teoria Ecológica do Desenvolvimento Humano. 
Observa-se na literatura internacional que, mesmo com a as recomendações para os estudos relacionados a migração e refúgio, poucos pesquisadores têm aplicado a Teoria dos Sistemas Ecológicos e a Teoria do Modelo Bioecológico (incluindo o Processo-Pessoa-Contexto-Tempo ou PPCT), ambas de Bronfenbrenner (Bronfenbrenner \& Morris, 2007), para compreender e auxiliar as populações migrantes em diferentes aspectos, tais como a saúde mental e a educação (Brady, 2019; Carvalho et al., 2018). Os profissionais da saúde mental, ou outras áreas relacionadas a este contexto, encontram dificuldades em oferecer esses serviços aos migrantes. Em especial, para compreender e avaliar as experiências e preocupações desta população, através das diversas competências multiculturais existentes, em face aos escassos recursos metodológicos para investigar fenômenos específicos como os deslocamentos forçados provocados por barragens (Carvalho e Silva, 2018).

A integração dos estudos da representação e dos contextos via o método fílmico implica a abordagem ecológica, que permite apreender a "situação total" - o conhecimento integrado da problemática (Ramos, 2003). Assim, na estratégia de ação o investigador torna-se participante, obedece as regras da cenografia (elementos sonoros e visuais, expressão do sensível, identificação do objeto, automise en scèn) e adota a Antropologia Partilhada, que é mostrar e desenvolver as imagens com os protagonistas (de France, 2000). A posição do investigador no espaço (ponto de observação) privilegia os pontos situados no meio da ação (Ramos, 2009).

Os instrumentos de pesquisas desenvolvidos a partir de imagens sonoras são privilegiados porque fornecem dados sobre as relações sociais e familiares, e das representações dos indivíduos e grupos (Ramos, 2003). Os filmes registram atividades e comportamentos que são elementos da vida cotidiana e, portanto, favorecem a compreensão das relações complexas individuais e coletivas. Os estilos culturais, comunicacionais e educativos, as práticas de cuidados, de saúde e de educação, e os contextos em que ocorrem na comparação inter/transcultural (Serafim \& Ramos, 2014).

Anteriormente, o êxodo do campo à cidade era bastante comum na américa latina. Entretanto, segundo Spurrier (2013), no nível da subjetividade não se constituía uma situação de desenraizamento tão aguda. Este fenômeno contemporâneo se justifica pelas afinidades culturais, das pessoas deslocadas, encontradas nos ambientes de interação não serem tão distantes e pela facilidade de livre circulação entre o local de origem e o local de residência. Portanto, é relevante compreender os processos internos dos indivíduos diante das motivações que os levam a deixarem o seu local de origem. As diversas transformações, nos vários níveis de sistemas individuais e contextuais dos atingidos por barragens, demandam o desenvolvimento de ferramentas ou métodos de avaliação que considerem essas mudanças (Athayde et al., 2019; Carvalho e Silva, 2018).

Aqui se insere o Reassentamento Pinheirópolis Rural, cujas famílias foram deslocadas pela construção da UHE Luís Eduardo Magalhães em 2001. A previsão dos impactos socioambientais, provenientes do barreamento do rio Tocantins, foi norteada pelos Estudos de Impactos Ambientais (EIA) e um Relatório de Impactos sobre o Meio Ambiente (RIMA) (CELTINS, 1996). Foram aplicados, para reduzir ou compensar o impacto, programas de relocação e de remanejamento da população, além da adequação de serviços públicos durante a construção do empreendimento e a reurbanização.

\section{MÉTODO}

Trata-se de uma análise fílmica do documentário "Pinheirópolis: vida, festa, futuro..." de 1 hora e 13 minutos, produzido em agosto de 2000 pela In'video Produções e Publicidades de Porto Nacional-TO e dirigido por José Iramar. O filme está na versão DVD gravado por uma câmera filmadora Panasonic hmc 40, originalmente em formato VHS. Ele foi financiado pela INVESTCO, um consórcio de empresas específico para construir e gerenciar a barragem de Lajeado, com o objetivo de registrar e preservar a memória das famílias sobre o antigo povoado. Atualmente o filme está disponível na videoteca da escola no reassentamento.

As imagens foram registradas em Porto Nacional-TO. Localizado na região central do estado, a $52 \mathrm{~km}$ da capital Palmas, o município tem uma área total de $4.449,918 \mathrm{~km}^{2}$ e uma população estimada em 49.146 habitantes (Instituto Brasileiro de Geografia e Estatística [IBGE], 2010). O bioma predominante é o cerrado e a sua economia gira em torno da agropecuária e do turismo cultural. O cenário é a antiga comunidade Pinheirópolis, que se situava à margem do rio Tocantins, em frente ao núcleo urbano da cidade. Neste local encontravam-se as famílias que foram deslocadas para a construção da UHE Luís Eduardo Magalhães. Na época foram identificadas 21 famílias e 347 indivíduos impactados (CELTINS, 1996).

A obra retrata o festejo ao Padroeiro do povoado, São Domingos, em agosto do último ano antes do barreamento do lago e, consequentemente, do deslocamento para a nova localidade. Na obra estão incluídos os quatro elementos da cenografia: sons, imagens narração e entrevistas (Ramos, 2003). São apresentadas as imagens vivas das casas, igreja, escola, centro comunitário, ruas, pessoas e famílias, nos ambientes públicos e privados, rituais, cobertura vegetal e animais. Também foram gravadas imagens impressas concedidas por uma entrevistada. Além das músicas cantadas 
pelos participantes, foi introduzida uma trilha sonora que servia para auxiliar a senso percepção de algumas imagens sem voz ativa, na rolagem dos créditos e nas trocas de cenas.

$\mathrm{O}$ narrador, de voz passiva, facilitou as aberturas e fechamentos das cenas através da apresentação dos dados históricos, sociais e econômicos de Pinheirópolis. Os entrevistados eram moradores da comunidade de todas as gerações. Os registros das falas são acompanhados pelas identificações dos participantes por meio das imagens visuais e das legendas escritas. Os participantes eram pessoas oriundas dessas famílias residentes no povoado com exceção dos registros verbais do narrador e do padre. Foram filmadas 26 entrevistas com os moradores, divididas igualmente entre mulheres e homens. Duas entrevistadas eram adolescentes e o restante se dividia entre adultos e idosos.

Para a análise dos dados, o filme foi executado no Power DVD versão 12.0.3.3709. Foram identificados 15 recortes editados provavelmente por organização temporal. Desta sequência foram formuladas, a partir de revisões por pares, as categorias que compõem o panorama geral da obra: a) formação do povoado b) atividades econômicas c) reações/ sentimentos ao deslocamento d) o último festejo e o luto antecipatório. Estas se deram por meio de codificação aberta (Flick, 2014) da frequência das imagens, acompanhadas das narrativas, e da contagem das frequências de repetições no endereço wordclouds.com - um gerador de nuvens de palavras e etiquetas online (Tabela 1).

O caso apresentado neste estudo foi extraído da pesquisa Comunidades ribeirinhas impactadas por barragens, aprovado pelo Comitê de Ética em Pesquisa da Universidade de Brasília, sob o registro CAAE: 70302016.8.0000.5540 e o Parecer $n^{\circ} 2.163 .238$, seguindo as normas da Resolução $n^{\circ} 466 / 12$ do Conselho Nacional de Saúde do Ministério da Saúde, que trata de ética em pesquisa com seres humanos conforme constou no Termo de Consentimento Livre e Esclarecido (TCLE). Foi concedida a utilização de todas as imagens, sons e narrativas do documentário, bem como a identificação dos participantes no documentário por meio da assinatura do termo de consentimento da Diretora Administrativa da I'nvideo Produções.

Tabela 1

Categorias e nuvens de palavras

\begin{tabular}{|c|c|c|}
\hline Categorias & Tempo Encerramento & Nuvens de palavras \\
\hline Formação do povoado & $14 \mathrm{~m}: 06 \mathrm{~s}$ & $\begin{array}{l}\text { Alunos (7); Pinheirópolis (7); Escola (6); Casa- Velha (5); Posto de saúde (4); } \\
\text { Professora (4); Município (2); Igreja (2); Colégio (2); D. Alano (2); Lamparina (1); } \\
\text { Água (1); Comerciante (2); Festeiro (2); Capitão do Mastro (2). }\end{array}$ \\
\hline Atividades econômicas & $15 \mathrm{~m}: 44 \mathrm{~s}$ & $\begin{array}{l}\text { Agricultura (1); Alimentação (1); Sentimento (1); Comunidade (1); Bichinhos (1); } \\
\text { Plantação (1); Galinha (1); Horta (1); Limão (1); Criação (1); Pato (1); Peru (1). }\end{array}$ \\
\hline $\begin{array}{l}\text { Reações/sentimentos ao } \\
\text { deslocamento. }\end{array}$ & $19: 15$ & $\begin{array}{l}\text { Lugar (6); Povoado (3); Deixar (3); Mudar (3); Sair (3); Água (3); Preocupação (2); } \\
\text { Chácara (2); Frutas (2); Triste (2); Tranquilidade (1). }\end{array}$ \\
\hline $\begin{array}{l}\text { O último festejo e o luto } \\
\text { antecipatório. }\end{array}$ & $1 \mathrm{~h}: 17 \mathrm{~m}$ & $\begin{array}{l}\text { São Domingos (8); Tradição (4); Continuar (2); Comunidade (1); Cultura (1); } \\
\text { Povoado (1); Expectativa (1). }\end{array}$ \\
\hline
\end{tabular}

\section{RESULTADOS}

Com um número significativo de palavras levantadas, elaborou-se a codificação axial e seletiva - formulação da story line (Flick, 2014), onde um conceito (Teoria dos Sistemas Bioecológicos) é anexado ao fenômeno central do estudo (deslocamentos forçados) e relacionado às categorias (Documentário). A figura 2 apresenta 0 resultado final da codificação axial em consonância com os núcleos "Processo - Pessoa - Contexto - Tempo" (PPCT) operantes no microssistema do desenvolvimento humano (Bronfenbrenner, 1988).

Compreende-se, a priori, que o PPCT são categorias de análise mais amplas que as elaboradas a partir do documentário, logo, a articulação entre as categorias elencadas a partir do filme e os núcleos da Teoria dos Sistemas Bioecológicos aumentam a compreensão sobre os sistemas individuais, sociais e culturais da comunidade atingida. A análise do documentário "Pinheirópolis: vida, festa futuro", filmado um ano anterior a relocação dos moradores, teve a participação das diferentes gerações - pais, avós e jovens, provenientes de diferentes extratos sociais. Ademais, este recurso possibilitou observar as experiências nos sistemas anteriores ao tempo presente.

\section{Formação do Povoado}

Originário da fazenda Presídio, conhecida como "Grugulho", os primeiros 08 minutos das cenas apresentam Pinheirópolis distante $12 \mathrm{~km}$ de Porto Nacional, banhado por três ribeirões: Itaboca, Presídio e Carmo, e as margens da BR Belém-Brasília. As narrativas descrevem o povoamento, as primeiras famílias, a dimensão espacial e a ausência de infraestrutura como posto fiscal, pavimentação, água encanada e energia elétrica. A comunidade foi se desenvolvendo a partir do processo migratório de diferentes famílias. 


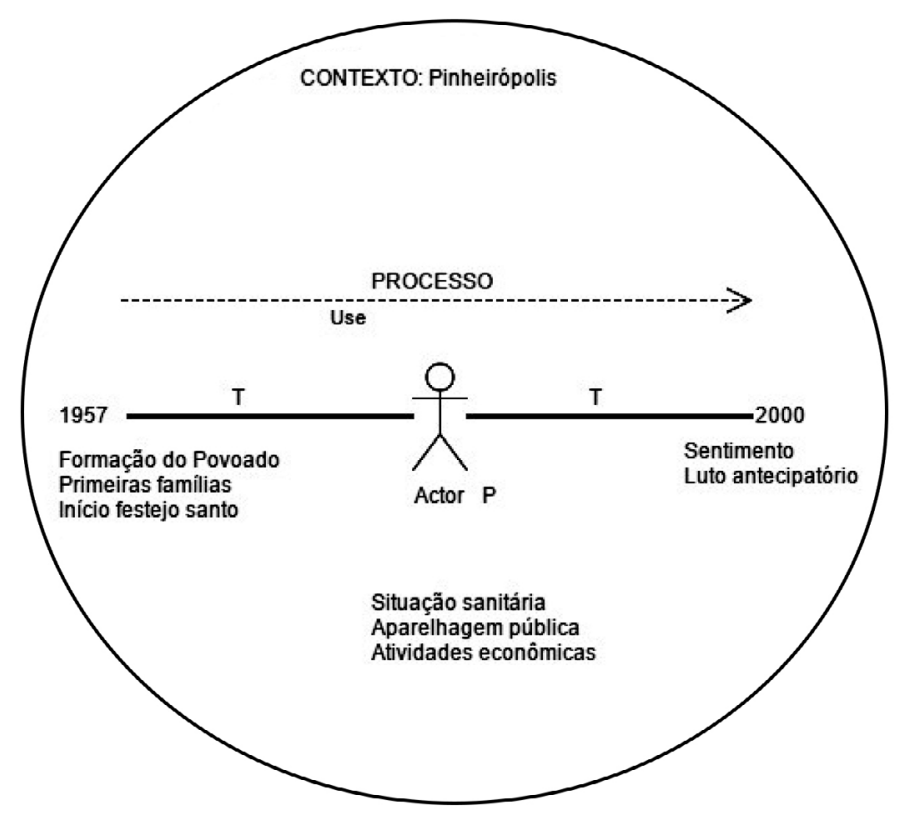

Figura 2. Processo, Pessoa, Contexto e o Tempo.

Em 1957 chegou na região a Professora Maria Telí, após o loteamento de parte da fazenda de propriedade do Sr. Rosário Pinheiro, para expandir o povoado que crescia prosperamente. "Dom Alano soube que tinha uma professora e queria ir lá pra conhecer. Ele esteve lá e disse que ia fazer uma igreja porque estragava minha casa. Aí mandou construir a igreja pertinho. Eu mudei a escola pra lá." (Professora Maria Telí, 11m01s).

O crescimento populacional previsto sobrecarregou a escola e mesmo com a ajuda da igreja foi necessária a contratação de mais duas professoras, atendendo uma média de 100 alunos. A partir de 1966, por influência do forte vínculo religioso representado pela figura de Dom Alano, um morador inicia os festejos à São Domingos.

\section{Atividades Econômicas}

A construção da ponte sobre o rio Tocantins no final da década de 70 desviou a estrada que passava por dentro do povoado. Por consequência, houve a decadência das atividades econômicas, tendo as famílias que se sustentarem com coletas e vendas de frutos cultivados nos quintais de grande extensão. "Hoje a gente se encontra na faixa de 1000 habitantes, e é uma comunidade que vive da agricultura, da coleta de frutos, plantação de hortas caseiras, esse tipo de coisa assim." (Luzia Lopes de Souza, 16m35s). A fim de motivar a geração de renda dos moradores, o posto comunitário disponibilizava mudas agrícolas para auxiliar a alimentação das famílias. Pinheirópolis era considerada a capital do caju e da manga pelos moradores das regiões circunvizinhas.

\section{Reações/Sentimentos ao Deslocamento}

"O sentimento é grande porque pra formar outro terreno desse aqui, do jeito que o meu está, é a mesma coisa que cortar o meu coração. Não é fácil. (Cícero Pinheiro Colasso, $17 \mathrm{~m} 22 \mathrm{~s})$ ". A formação do lago da Barragem Luís Eduardo Magalhães um ano seguinte removeria as famílias das suas propriedades. A opinião dos moradores era de que a água não alcançaria o núcleo urbano, pois Lajeado estava geograficamente distante. Havia a incerteza do local onde passariam a residir, a sensação de ansiedade para receber as suas indenizações e sair, a insatisfação em mudar e deixar o lugar, as chácaras, as frutas, a tranquilidade.

Havia também a preocupação de deixar a história registrada, pois sabiam que precisavam mudar e tudo aquilo acabaria. Queriam deixar para as gerações futuras as memórias de um povoado que durou mais de 30 anos, foi importante para o desenvolvimento do município e que acabou em decorrência da Usina do Lajeado.

\section{O Último Festejo e o Luto Antecipatório}

No ano de 2000, a população de Pinheirópolis realizou uma grande festa ao padroeiro São Domingos. A folia, presente desde o surgimento do povoado, acompanhou os rituais religiosos. Nas cenas do festejo todos ajudavam, as crianças observavam as performances dos foliões, os festeiros dançavam a "Sussa" (uma espécie de bailado em que os homens e mulheres se movimentam ritmicamente em círculos). Algumas mulheres equilibravam uma garrafa de 
vidro na cabeça durante a dança. Foram empregados papéis, entre os moradores, durante a semana de festividade pagã e religiosa ao santo (Violeiro, dançarinos, imperador, capitão do mastro e rainha) e a bandeira do divino percorreu as residências das famílias que ofereceram fartos lanches com bolos, sucos e licores da região.

A festa invocou o sentimento de pertencimento na comunidade e atribuiu valor as relações familiares a exemplo da divisão do trabalho: "Ela (esposa do lado) me deu uma força muito grande. Porque sem ela ia ter dificuldades com essa festa. Vou sentir saudades daqui, mas é o destino. Então pra onde formos a festa será bem realizada." (Cícero Dias, Imperador do festejo, $49 \mathrm{~m} 20 \mathrm{~s}$ ).

Durante a noite, após uma procissão pelas ruas, a folia e os fiéis chegaram à igreja para a celebração da missa. Neste último festejo a São Domingos, a comunidade realizou um culto de agradecimento pelo tempo que moraram ali.
Falaram da expectativa de conservar a tradição, a cultura, e continuar com o sentimento comunitário existente no povoado.

No final, o documentário retomou as narrativas sobre o deslocamento, que foi enquadrada nesta categoria como a vivência do luto antecipatório. De modo geral, os moradores expuseram um sentimento negativo em relação a perda do lugar. Por mais que a comunidade permanecesse unida, com a mudança, observou-se o medo de não continuar os estilos de vida individuais e comunitários: "Pra gente não perder as nossas raízes, porque todo o ser humano, toda sociedade tem que ter uma cultura. Quando se perde essa cultura, a gente perde a razão de viver, o sentido da vida." (Luzia Lopes de Souza, $01 \mathrm{~h} 10 \mathrm{~m})$. No momento, o lugar de relocação seria diferente e a vida nova, o que pareceu ser positivo, em detrimento ao medo do desconhecido.

\section{DISCUSSÃO}

$\mathrm{O}$ atendimento às necessidades imediatas das famílias deslocadas não é uma intervenção suficiente para sustentar a sobrevivência da comunidade após o deslocamento forçado (Athayde et al., 2019; Parente, 2015; Zagallo \& Ertzogue, 2018). É necessária uma abordagem holística e interdisciplinar para responder uma ampla gama de questões relacionadas aos processos individuais e contextuais antes, durante e após a remoção (Hirani \& Richter, 2019). Os aspectos que envolvem a saúde, o bem-estar e o desenvolvimento das populações deslocadas é essencial para alcançar as metas do desenvolvimento sustentável (Organização das Nações Unidas [ONU], 2017). Neste sentido, a partir da estrutura do PPCT, as categorias apresentadas nos resultados serão discutidas em constante interação com os diferentes sistemas.

Bronfenbrenner (1988) adota a fórmula sobre o desenvolvimento humano a partir da ideia de que ele é uma "função" da pessoa e do ambiente $[\mathrm{D}=f(\mathrm{PE})]$. É a partir das interações com e entre os sistemas circundantes - como a família, escola e ambiente comunitário (microssistema e mesossistema), a ampla sociedade e as instituições (exossistema), a cultura e as políticas (macrossistema) - que se promove ou tolhe o crescimento. Portanto, de acordo com a Teoria dos Sistemas Bioecológicos, qualquer mudança em uma das propriedades de interação nos sistemas pode mudar o curso do desenvolvimento (Brady, 2019; Hirani \& Richter, 2019; Paat, 2013).

O desenvolvimento da pessoa ocorre através do engajamento em interações repetidas e cada vez mais complexas com outros indivíduos e objetos no ambiente. Essas interações são conhecidas como processos proximais e são cruciais para direcionar o crescimento (Bronfenbrenner \& Morris, 1998). Eles estão entrelaçados entre a pessoa e o contexto com as respectivas influências bidirecionais: o indivíduo pode interagir com o ambiente ou responder diferentemente às interações baseadas nele (Carvalho e Silva, 2018).

O filme analisado acrescentou elementos importantes sobre a experiência do processo do deslocamento, tais como a intensão das famílias em se preservar os aspectos culturais, religiosos, históricos e econômicos presentes na comunidade. O envolvimento da escola e da igreja em toda articulação desde o surgimento até a extinção do povoado foram marcadores dos valores e rituais elaborados pelas famílias transgeracionais naquela cultura. A preservação desses elementos nos padrões familiares e os conjuntos de regras, mesmo que possam variar de família para família, está condicionada pela classe social à qual eles pertencem (Brady, 2019; Bucher-Maluschke et al., 2017; Carvalho e Silva, 2018; Hirani \& Richter, 2019). Neste sentido, o processo pode ocorrer desde uma perspectiva universal quanto pelos processos proximais recorrentes no microssistema (Paat, 2013).

De acordo com a abordagem ecológica, as características individuais em algum ponto no tempo podem influenciar diretamente os resultados em pontos temporais subjacentes, afetando as interações no presente (Bronfenbrenner \& Morris, 2007). O documentário não dispõe de informações sobre os traços individuais dos moradores, entretanto, as cenas representaram a predominância da população negra. Os rituais pagãos e religiosos acompanhados de tambores construídos de madeira e pele de animais são uma característica das populações tradicionais do Tocantins, majoritariamente remanescentes de quilombos (Andrade et al., 2013).

O luto antecipatório dos moradores observado nas imagens sonoras pode ser desenvolvido na ótica de aspectos descritos pela literatura tais como a perda, trauma e separação 
(Athayde \& Silva-Lugo, 2018; Silva Marques et al., 2018; Hirani \& Richter, 2019; Jesus \& Ertzogue, 2018; Paat, 2013; Zagallo \& Ertzogue, 2018). A ocorrência do enchimento do rio, os decorrentes sentimentos, a insegurança, o medo e as promessas das melhorias no novo reassentamento influenciaram no apego, e na relação com o ambiente, de modo que houve uma ambivalência de sentimentos entre os entrevistados. Foram repercutidos, durante a expressão do luto antecipatório, $\mathrm{o}$ anseio entre partir para outras terras e permanecer junto com a comunidade e suas tradições.

O processo temporal, funcional e o simbólico do apego ao lugar contribuem para a manutenção do desejo de permanecer na propriedade (Alves et al., 2015). O trabalho de Fried (1963), pioneiro para a teoria do apego ao lugar, avaliou as reações de moradores deslocados de um prédio habitacional nos Estados Unidos. Os resultados revelaram um intenso sofrimento psicológico nos impactados, algos que foi assemelhado à experiência da perda de um ente querido. A principal característica do apego é o vínculo afetivo positivo entre a pessoa e um lugar, mais especificamente a forte tendência de a pessoa permanecer próxima a um determinado espaço (Alves et al., 2015).

Todavia, o legado de Bronfenbrenner sobre o desenvolvimento humano tem motivado os psicólogos a considerarem que os contextos individuais, ambientais e sociais são importantes para o desenvolvimento das populações migrantes (Brady, 2019; Bronfenbrenner \& Morris, 2007; Carvalho e Silva, 2018; Paat, 2013). A família é considerada o sistema mais influente no microssistema por ser a mais próxima, estudada e poderosa na vida da pessoa (Hirani \& Richter, 2019). O desenvolvimento, a linguagem, a saúde, as crenças e assim por diante são todos dependentes durante a entrada e o feedback do comportamento-relacionado dentro do núcleo familiar (Bronfenbrenner, 1986).

Atinentes à esta questão, Silva et al. (2011) adaptaram um instrumento de avaliação familiar ao contexto ribeirinho amazônico. Este processo utilizou a adição de elementos da cultura durante a construção de tarefas apresentadas às famílias focais. Os resultados revelaram a hierarquia dos papéis e a predominância da liderança masculina. Contraditoriamente, no contexto das famílias ribeirinhas de Pinheirópolis, o documentário apresentou, na maioria das cenas, a participação das mulheres nos rituais festivos e exercendo o papel de líderes na comunidade. Elas ocupavam também os espaços de fala durante o festejo à São Domingos, tendo sido entrevistadas mulheres de diferentes gerações em situação de pobreza.

Para Bronfenbrenner (1986), a pobreza é uma característica contextual, pois marca as pessoas e as suas relações. O processo do deslocamento provoca uma ruptura no indivíduo e nas famílias, onde o conceito de pobreza se torna volúvel às condições interpeladas no contexto
(Carvalho e Silva \& Bucher-Maluschke, 2018). No caso dos ribeirinhos amazônicos, apesar da abundante biodiversidade, eles têm poucas oportunidades sociais de desenvolvimento devido as diversas dificuldades, como falta de saneamento básico, de energia elétrica, água potável, restrições de saúde e educação (Athayde et al., 2019; Parente, 2015; Zagallo \& Ertzogue, 2018)

A propósito, as nuvens de palavras construídas na análise identificaram uma baixa repetição dos termos relacionados as atividades econômicas. Entretanto, observou-se a diversidade de palavras, sem repetições, relacionadas ao sustento das famílias através do cultivo e da coleta do que o ambiente físico os proporcionava. Estes termos, agregados a um forte valor sentimental, ressaltaram a continuidade do trabalho para as famílias sobre aquilo que elas sabiam fazer por gerações. O deslocamento forçado dos povos ribeirinhos, em detrimento da extensão do agronegócio, resultam na necessidade de suprir condições que garantam a sobrevivência por meio do trabalho, da assistência à saúde e do acesso à escola (Athayde \& Silva-Lugo, 2018).

Os conteúdos do documentário analisado atravessam os períodos de 1957 à 2000, época de intensas transformações no território do atual estado do Tocantins para viabilizar um projeto de desenvolvimento que passava pela integração do norte do país através de um corredor, fluvial e terrestre, em que o Tocantins tinha um papel estratégico (Andrade et al., 2013). A vocação do Estado, como a região do Eldorado brasileiro, faz ainda dele um organizador e gestor de políticas territoriais que promovem a expansão por meio da construção de estradas, ferrovias, hidrovias e principalmente hidrelétricas (Parente, 2015).

Bronfenbrenner e Morris (2007) afirmam que os eventos promotores das mudanças significativas são contingentes no tempo da vida do indivíduo. Carvalho e Silva e Bucher-Maluschke (2018) assinalaram a importância do embasamento das teorias psicológicas para entender as experiências do deslocamento forçado, oferecidas por diferentes lentes temporais, e em distintos períodos do desenvolvimento e das transições no ciclo vital. A preposição do tempo, no nível macro, aponta para a importância dos eventos históricos na formação do curso de vida do indivíduo (Bronfenbrenner \& Morris, 2007).

As informações oferecidas pelo documentário em discussão se remetem a um tempo passado, que traz aos pesquisadores, no tempo presente, o resgate dos conteúdos vividos (de France, 2000). No sentindo de compreender os sistemas no curso do tempo, a análise ecológica do método fílmico privilegiou e enriqueceu os dados, pois as imagens em ação transpassaram as vivências para além do resgate da memória. As imagens e as narrativas refletiram visualmente a performance e a corporeidade das experiências vividas em Pinheirópolis. 


\section{CONSIDERAÇÕES FINAIS}

Esta análise ecológica de um documentário buscou compreender as experiências das famílias impactadas no contexto do deslocamento forçado em uma comunidade ribeirinha na Amazônia. A partir das nuvens de palavras, construídas a partir do número de repetições e da identificação dos termos nas narrativas do documentário, foi possível identificar as categorias de análise, que foram discutidas com base nos apontamentos teóricos da Teoria dos Sistemas Ecológicos e nas propriedades PPCT.

$\mathrm{O}$ método fílmico facilitou a macro e a microanálise temporal das atividades e das interações, o que trouxe a percepção do anseio dos moradores entre partir para outras terras ou permanecer junto com a comunidade. Entretanto, essa metodologia apresenta fatores limitantes para uma compreensão dos aspectos individuais das pessoas atingidas. Neste estudo, por se tratar de um evento ocorrida há mais de uma década, a escassez de outros registros e fontes documentais limitou explorar outros olhares além do diretor do documentário.
A interpretação dos dados, com foco em um paradigma ecológico, possibilitou, de toda maneira, a associação entre as famílias e outros sistemas ecológicos como a escola, a igreja, a vizinhança e a rede de apoio. A aplicação de uma abordagem teórica holística é, portanto, crucial na avaliação dos impactos emocionais provocados pelo deslocamento forçado, tendo em vista que as famílias não existem de maneira isolada, mas articuladas com uma ampla estrutura social, interconectadas com outras instituições e domínios sociais.

Ademais, os resultados apontaram que os impactos dos atingidos por barragem vão além da perda das atividades econômicas. Os deslocamentos forçados na Amazônia por projetos ambientais provocam repercussões psicológicas oriundas dessas experiências no desenvolvimento dos impactados, da família e da comunidade. Sugere-se a utilização da análise ecológica do método fílmico como um recurso para a avaliação dos impactos nas rotinas e nas dinâmicas relacionais dos atingidos por barragens e para a construção dos planos de compensações.

\section{REFERÊNCIAS}

Alves, R. B., Kuhnen, A., \& Battiston, M. (2015). "Lar doce lar": Apego ao lugar em área de risco diante de desastres naturais. Psico, 46(2), 155. https://doi.org/10.15448/19808623.2015.2.17484

Andrade, K., Flores, M. F., \& Bodnar, R. (2013). Populações tradicionais no Tocantins: cultura e saberes de comunidades quilombolas. Gráfica e Editora América.

APA. (2012). Report of the APA task force on immigration: Executive summary. APA.

Athayde, S., Duarte, C. G., Gallardo, A. L. C. F., Moretto, E. M., Sangoi, L. A., Dibo, A. P. A., Siqueira-Gay, J., \& Sánchez, L. E. (2019). Improving policies and instruments to address cumulative impacts of small hydropower in the Amazon. Energy Policy, 132(May), 265-271. https://doi.org/10.1016/j. enpol.2019.05.003

Athayde, S., \& Silva-Lugo, J. (2018). Adaptive Strategies to displacement and environmental change among the Kaiabi Indigenous People of the Brazilian Amazon. Society and Natural Resources, 31(6), 666-682. https://doi.org/10.1080/ 08941920.2018 .1426801

Brady, S. E. (2019). Meeting the needs of migrants: Applying the bioecological systems theory to assess multicultural competency in mental health. Proquest. https://search.proquest. com/openview/e920411ab25fee2dd8518cf14c1b4aca/1?pq-or igsite $=$ gscholar \&cbl $=18750 \&$ diss $=y$

Bronfenbrenner, U. (1986). Ecology of the family as a context for human development: Research perspectives. Developmental Psychology, 22(6), 723-742. https://doi.org/10.1037/00121649.22.6.723

Bronfenbrenner, U. (1988). Interacting systems in human development. Research paradigms: Present and future. In N. Bolger, A. Caspi, G. Downey, \& M. Moorehouse (Eds.), Persons in context: Developmental processes (pp. 25-43). http://www.loc.gov/catdir/toc/cam029/87036765.html
Bronfenbrenner, U., \& Morris, P. A. (1998). The ecology of developmental processes. In Handbook of Child Psychology (1st ed., pp. 993-1028). John Wiley \& Sons, Inc.

Bronfenbrenner, U., \& Morris, P. A. (2007). The Bioecological Model of Human Development. In Handbook of Child Psychology (pp. 793-828). https://doi.org/10.1002/9780470147658.chpsy0114

Bucher-Maluschke, J., Gondim, M. de F., \& Pedroso, J. da S. da S. (2017). The effects of migration on family relationships: Case studies. International Journal of Migration, Health and Social Care, 13(2), IJMHSC-05-2015-0016. https://doi.org/10.1108/ IJMHSC-05-2015-0016

Carvalho e Silva, J. (2018). Impactos individuais e contextuais do deslocamento forçado na comunidade [Tese de doutorado]. Repositório UnB. https://repositorio.unb.br/ handle/10482/34257

Carvalho e Silva, J., \& Bucher-Maluschke, J. S. N. F. (2018). Psychology of forced displacement and migration: A systematic review of the scientific literature. Estudos de Psicologia (Campinas), 35(2), 127-136. https://doi.org/10.1590/198202752018000200002

Carvalho e Silva, J., \& Ertzogue, M. H. (2015). Cosmologia , paisagem, lugar e o método fenomenológico: Possíveis reflexões em uma cidade impactada por barragem. PRACS: Revista de Humaninadades do Curso de Ciências Sociais da UNIFAP, 8(1), 11-24. https://periodicos.unifap.br/index.php/ pracs/article/view/1149

CELTINS. (1996). RIMA Relatório de Impacto sobre o Meio Ambiente. CELTINS.

de France, C. (2000). Antropologia fílmica. Uma génese difícil, mas promissora. In C. de France (Ed.), Do filme etnográfico à antropologia filmica2 (pp. 17-42). Editora da UNICAMP.

Flick, U. (2014). An introduction to qualitative research (5th ed.). Sage.

Fried, M. (1963). Grieving for a lost home. In J. Q. Wilson (Ed.), Urban renewal: The record and the controversy (pp. 151-171). The M.I.T Press. 
Hirani, S. A. A., \& Richter, S. (2019). Maternal and child health during forced displacement. Journal of Nursing Scholarship, 51(3), 252-261. https://doi.org/10.1111/jnu.12460

Instituto Brasileiro de Geografia e Estatística. (2010). Censo 2010. http://censo2010.ibge.gov.br/

Instituto Igarapé. (2018). Dados sobre migrações forçadas. https:// migracoes.igarape.org.br/

Jesus, B. M. De, \& Ertzogue, M. H. (2018). Sobre a saudade de um rio: Perdas simbólicas dos ribeirinhos do Tocantins. DESAFIOS - Revista Interdisciplinar da Universidade Federal do Tocantins, 5(Especial), 169-177. https://doi.org/10.20873/ uft.2359-3652.2018v5nEspecialp169

Menestrino, E., \& Parente, T. G. (2011). O estudo das territorialidades dos povos tradicionais impactados pelos Empreendimentos Hidrelétricos no Tocantins. Brazilian Geografhical Journal: Geosciences and Humanities Research Medim, 2(1), 1-19. http://www.seer.ufu.br/index.php/braziliangeojournal/article/ view/9157

Organização das Nações Unidas. (2017). Draft report of the Working Group on the Universal Periodic Review Brazil. http://acnudh. org/wp-content/uploads/2017/05/A_HRC_WG.6_27_L.9_ Brazil.pdf

Paat, Y. F. (2013). Working with immigrant children and their Families: An application of Bronfenbrenner's Ecological Systems Theory. Journal of Human Behavior in the Social Environment, 23(8), 954-966. https://doi.org/10.1080/10911 359.2013.800007

Parente, T. G. (2015). (In)visibilidade de atores no processo de reassentamentos da Usina Hidrelétrica Luís Eduardo Magalhães, no Tocantins. Revista Territórios e Fronteiras, 8(1), 149. https://doi.org/10.22228/rt-f.v8i1.296

Pinto, L. C. (2012). Os projectos hidrelétricos como causa dos deslocamentos populacionais: Migrações forçadas em nome do desenvolvimento [Dissertação de mestrado]. Repositório Universidade Nova. https://run.unl.pt/handle/10362/9357

Ramos, N. (2003). Perspectivas metodológicas em investigação: O contributo do método fílmico. Revista Portuguesa de Pedagogia, 37(3), 35-62.

Ramos, N. (2009). Diversidade cultural, educação e comunicação intercultural - Políticas e estratégias de promoção do diálogo intercultural. Revista Educação em Questão, 34(20), 9-32. https://periodicos.ufrn.br/educacaoemquestao/article/ view/3941

Serafim, J. F., \& Ramos, N. (2014). Representação da doença no cinema documentário autobiográfico. In A. C. Valente \& R. Capucho (Eds.), Avanca Cinema 2014 (1st ed., pp. 896-901). Edições Cine-Clube de Avanca.

Serafim, J. F., \& Ramos, N. (2016). Cinema documentário e representação da migração. In A. C. Valente \& R. Capucho (Eds.), Avanca Cinema. International Conference 2016 (pp. 464-470). Edições Cine-Clube de Avanca.

Silva, S. de S. da C., Santos, T. M. dos, Pontes, F. A. R., \& BucherMaluschke, J. S. N. F. (2011). Avaliação de famílias ribeirinhas : Uma proposta adaptada ao contexto. Revista Interinstitucional de Psicologia , 4(2), 253-263. http://pepsic.bvsalud.org/scielo. php?script $=$ sci_arttext\&pid=S1983-82202011000200007

Silva Marques, G., Teixeira da Cruz, F. K., Giongo, C. R., \& Rosa Mendes, J. M. (2018). Deslocamento forçado e saúde mental: O caso da hidrelétrica de Itá. Revista de Estudios Sociales, 20(66), 30-41. https://doi.org/10.7440/res66.2018.04

Spurrier, P. O. de. (2013). Migraciones y efectos en la subjetividad, hoy. Ajayu, 11(1), 121-132. http://www.scielo.org.bo/scielo. php?script $=$ sci_arttext\&pid $=$ S2077-21612013000100006

Zagallo, A. D. A., \& Ertzogue, M. H. (2018). "Os sentimentos eles nunca vão indenizar": Tecendo memórias de mulheres ribeirinhas atingidas por barragens. INTERthesis, 15(2), 91-108. https://doi.org/10.5007/1807-1384.2018v15n3p91 